\title{
Nota sobre o I Seminário das Escolas Técnicas do SUS do Estado de São Paulo Note on $1^{\text {st }}$ Seminar of the Technical Schools of SUS of the State of São Paulo
}

\author{
Vera Lúcia de Barros \\ Professora do Centro Universitário São Camilo e da Escola Técnica \\ do SUS da Secretaria Municipal da Saúde de São Paulo. \\ E-mail: velubaळuol.com.br
}

\section{Introdução}

A educação profissional de saúde de nível técnico vem sendo realizada sistematicamente no estado de São Paulo desde 1952 e, mais recentemente, pelo município de São Paulo (1990), sob a responsabilidade das secretarias da saúde do estado e do município.

Com a implantação do Sistema Único de Saúde (SUS) atribui-se às escolas o papel estratégico fundamental de proposição e implementação da política de educação para o SUS, tanto do ordenamento da formação dos profissionais de saúde como na adequação dos perfis profissionais e educação permanente dos trabalhadores (artigo 6, lei 8o8o de 19/og/9o). Contribuem, assim, na transformação das práticas de saúde, no campo da formação, da gestão, da atenção e do controle social, no sentido da integralidade, da humanização da atenção e da responsabilização às necessidades de saúde da população.

O eixo orientador da educação profissional é o processo de trabalho em saúde, tendo como referência as concepções contidas na Reforma Sanitária, que orientaram a institucionalização do SUS.

As escolas estaduais, bem como a escola municipal, vêm desenvolvendo cursos de formação conforme preconizado pelo SUS. Carecem, entretanto, de efetiva integração, no sentido de apoio mútuo e da colaboração de outras instituições nacionais ou internacionais, na perspectiva de fortalecer e facilitar a educação profissional.

Apesar da existência institucional da rede de escolas técnicas do SUS - RET-SUS, dos polos de educação permanente em saúde, que já objetivam a integração entre instituições formadoras, faz-se necessário o estabelecimento de outras estratégias para efetivar essa integração.

Neste contexto, foi realizado o I Seminário das Escolas Técnicas do SUS do Estado de São Paulo, com os seguintes objetivos: 
- proporcionar a formação de rede integrativa para o fortalecimento das Escolas Técnicas do SUS (ETSUS) de São Paulo;

- refletir sobre as práticas de ensino-aprendizagem das ETSUS nos cenários Nacional, Estadual e Municipal;

- propiciar a integração entre as ETSUS do Estado de São Paulo;

- fornecer subsídio teórico-metodológico aos profissionais integrantes das ETSUS;

- estabelecer mecanismos de cooperação entre as instituições participantes.

\section{Do conteúdo do seminário}

O seminário, realizado em parceria com a Associação Paulista de Saúde Pública (APSP), ocupou um dos espaços das atividades do pré-congresso do X Congresso Paulista de Saúde Pública, nos dias 27 e 28 de outubro de 2007 , na cidade de São Pedro.

Contou com a participação de 250 profissionais, entre docentes, alunos e coordenadores, que atuam nas seis escolas estaduais e na escola municipal de São Paulo.

O conteúdo do seminário teve como tema eixo "Educação e Trabalho". Sua programação científica ocorreu conforme o planejado, com algumas alterações.

Um dos temas desenvolvidos contemplou os cenários nacional, estadual e municipal das ETSUS. Falas expostas por sujeitos com significativa participação na construção histórica desse processo.

As ETSUS são apresentadas como instâncias formadoras, voltadas para a formação de nível dos profissionais do SUS, com projeto político pedagógico apontado pela ETSUS-SP: o currículo integrado, o trabalho como principio educativo e a metodologia problematizadora.

Nessa perspectiva, a Educação pelo Trabalho, eixo temático do seminário, é abordada pelos professoresdoutores Marise Ramos e Ricardo Ribeiro. Professora Marise aborda "O Trabalho como Princípio Educativo", na perspectiva da implementação do Sistema Único de Saúde (SUS) e aprofunda nesse sentido o princípio da Integralidade. Professor Ricardo faz uma abordagem sobre o conceito de trabalho e a formação e aponta algumas orientações, ou princípios, que podem contribuir para a organização de programas de formação de adultos, como "a aprendizagem acontece ao longo da vida”.
Por último, com a intencionalidade de se estabelecer uma rede solidária entre as ETSUS participantes, foi desenvolvido o tema "Formação de Redes", na perspectiva do desafio do agir em rede, na compreensão de suas conexões, pontos de convergência e de bifurcação, respeitando as diversidades, superando as tensões e fortalecendo as convergências.

Ao final do evento, elaborou-se uma carta de proposta.

\section{Propostas do I Seminário das ETSUS do Estado de São Paulo Apresentadas na Plenária de Encerramento do X Congresso Paulista de Saúde Pública (São Pedro, 27 a 3I de outubro de 2007)}

As Escolas Técnicas do SUS (ETSUS) do Estado de São Paulo agradecem a acolhida do X Congresso Paulista de Saúde Pública e o apoio do Ministério da Saúde para a realização do I Seminário das ETSUS do Estado de São Paulo.

O Seminário teve como eixo central Educação e Trabalho e o objetivo de propiciar a formação de rede integrativa para o fortalecimento das Escolas Técnicas do SUS do Estado de São Paulo.

Participaram do evento cerca de 250 profissionais que atuam nas seis escolas estaduais e uma escola do município de São Paulo.

Na plenária final foram definidos os seguintes encaminhamentos de continuidade do processo:

1. elaboração e publicação do Relatório Final do I Seminário;

2. realização de oficinas locais em cada ETSUS para discussão e divulgação do relatório final;

3. realização do II Seminário das ETSUS do Estado de São Paulo no XI Congresso Paulista de Saúde Pública.

A plenária final recomenda, ainda, aos participantes do X Congresso Paulista de Saúde Pública:

1. incluir/rever nos Planos Plurianuais (PPAs) os seguintes tópicos, relacionados à formação de recursos humanos:

- diretrizes e metas mais qualificadas para a área de formação e desenvolvimento de Recursos Humanos (RH); - indicadores e metas de avaliação. 
2. incluir nos Planos de Saúde Municipais e Estaduais projetos de formação e desenvolvimento de RH, para serem desenvolvidos pelas ETSUS e áreas de desenvolvimento de RH;

3. definir linhas de investimentos para a criação, implementação e fortalecimento das ETSUS nos Planos Diretores de Investimento;

4. pautar no Colegiado de Gestão Regional a educação profissional de nível médio.

I Seminário das Escolas Técnicas do SUS do Estado de São Paulo

São Pedro, 28 de outubro de 2007. 